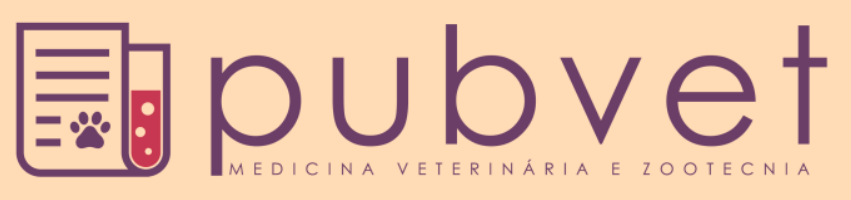

ISSN $1982-1263$

https://doi.org/10.22256/pubvet.v12n4a80.1-11

\title{
Abscesso hepático em bovinos: Revisão
}

\section{Rones Goulart de Paula Júnior ${ }^{\ominus 1 *}$, Pedro Paulo Tsuneda ${ }^{\ominus}$ 1, Luiz Eduardo Senra e Silva ${ }^{\ominus}$, Rodrigo Delbem Almeida ${ }^{\ominus 2}$, Núbia Bezerra do Nascimento Matos ${ }^{\bullet}$}

${ }^{1}$ Médico(a) Veterinário, doutorando em Ciência animal pela Universidade Federal de Mato Grosso - Cuiabá, Mato Grosso, Brasil. ${ }^{2}$ Médico(a) Veterinário, mestrando em Ciência animal pela Universidade Federal de Mato Grosso - Cuiabá, Mato Grosso, Brasil. ${ }^{3}$ Graduando(a) em Medicina Veterinária pela Universidade Federal de Mato Grosso - Cuiabá, Mato Grosso, Brasil.

*Autor para correspondência: E-mail: rones-junior@hotmail.com

RESUMO. Os abscessos hepáticos são considerados sequelas de quadros de acidose ruminal e ruminites em bovinos alimentados com dietas ricas em carboidratos altamente fermentáveis, e pobres em volumoso. O Fusobacterium necrophorum é o principal agente etiológico, e o segundo patógeno mais frequentemente isolado é o Arcanobacterium pyogenes, atualmente denominado de Trueperella pyogenes. Na maioria das vezes os abscessos hepáticos são diagnosticados e encontrados no exame post-mortem durante o abate dos bovinos, pois raramente há manifestação de sinais clínicos. Macroscopicamente eles são observados como uma área de inflamação purulenta, envolvida por uma cápsula de tecido conjuntivo fibroso, que pode variar em espessura e tamanho, atingindo até $15 \mathrm{~cm}$ de diâmetro. Os abscessos hepáticos são apontados como um enorme problema econômico para produtores e também para a indústria frigorifica, já que são associados a uma diminuição no consumo da dieta, ganho de peso, rendimento de carcaça e a condenação do fígado. Portanto, há uma busca incessante para prevenir e reduzir a incidência de abscessos hepáticos, principalmente por meios alternativos ao uso de antibióticos, como a produção de vacinas e a manipulação das dietas, uma vez que a utilização de antibióticos é contestada por diversos países devido ao risco de induzir a resistência antimicrobiana em humanos. Desta forma, o objetivo desta revisão é reunir e discutir informações a respeito da incidência dos abscessos hepáticos em bovinos, bem como sua importância econômica, etiologia, patogenia, diagnóstico e prevenção.

Palavras chave: antibióticos, dietas, ruminites

\section{Liver abscesses in cattle: Review}

ABSTRACT. Liver abscesses are considered sequelae of rumen acidosis and ruminits in cattle fed diets rich in highly fermentable carbohydrates and poor in roughage. Fusobacterium necrophorum is the main etiological agent and the second most frequently isolated pathogen is Arcanobacterium pyogenes, currently known as Trueperella pyogenes. Most of the time, liver abscesses are diagnosed and found in the postmortem examination during the slaughter of cattle, because there is rarely a manifestation of clinical signs. Macroscopically, liver abscesses are seen as an area of purulent inflammation, surrounded by a fibrous connective tissue capsule, which can vary in thickness and size, reaching up to $15 \mathrm{~cm}$ in diameter. Liver abscesses are identified as a huge economic problem for producers and also for the meat industry, since they are associated with a decrease in dietary intake, weight gain, carcass yield and the condemnation of the liver. Therefore, there is an incessant search to prevent and reduce the incidence of liver abscesses, mainly through alternative means to the use of antibiotics, such as the production of vaccines and the manipulation of the diets, since the use of antibiotics is contested by several countries due to the risk to induce antimicrobial resistance in humans. Thus, the objective of this review 
is to gather and discuss information about the incidence of liver abscesses in cattle, as well as their economic importance, etiology, pathogenesis, diagnosis and prevention.

Keywords: antibiotics, diets, ruminitis

\section{Absceso hepático en bovinos: Revisión}

RESUMEN. Los abscesos hepáticos se consideran secuelas de cuadros de acidosis ruminal y ruminitis en bovinos alimentados con dietas ricas en carbohidratos altamente fermentables, y pobres en forraje. El Fusobacterium necrophorum, es el principal agente etiológico, y el segundo patógeno más frecuentemente aislado es el Arcanobacterium pyogenes, actualmente denominado de Trueperella pyogenes. La mayoría de las veces los abscesos hepáticos son diagnosticados y encontrados en el examen post-mortem durante el sacrificio de los bovinos, pues raramente hay manifestación de signos clínicos. Macroscópicamente los abscesos hepáticos se observan como un área de inflamación purulenta, envuelta por una cápsula de tejido conjuntivo fibroso, que puede variar en espesor y tamaño, alcanzando hasta $15 \mathrm{~cm}$ de diámetro. Los abscesos hepáticos son señalados como un enorme problema económico para los productores y también para la industria frigorífica, ya que se asocian a una disminución en el consumo de la dieta, la ganancia de peso, el rendimiento de canal y la condena del hígado. Por lo tanto, hay una búsqueda incesante para prevenir y reducir la incidencia de abscesos hepáticos, principalmente por medios alternativos al uso de antibióticos, como la producción de vacunas y la manipulación de dietas, ya que la utilización de antibióticos es contestada por diversos países debido al riesgo de inducir resistencia antimicrobiana en humanos. De esta forma, el objetivo de esta revisión es reunir y discutir informaciones sobre la incidencia de los abscesos hepáticos en bovinos, así como su importancia económica, etiología, patogenia, diagnóstico y prevención.

Palabras clave: antibióticos, dietas, ruminitis

\section{Introdução}

Com o intuito de reduzir a idade ao abate, aumentar a taxa de desfrute, o giro do capital e consequentemente reduzir o ciclo de produção da pecuária, tem se empregado cada vez mais sistemas intensivos de produção, como os confinamentos que permitem ainda melhorar o acabamento de gordura na carcaça e a qualidade da carne (Prado, 2010, Vechiato et al., 2011). Desta forma, o uso de dietas ricas em concentrados energéticos tem se intensificado, e quando mal utilizadas, essas podem predispor ao surgimento de problemas metabólicos como acidose crônica, ruminites e consequentemente os abscessos hepáticos.

Os quadros de ruminites ocasionam uma lesão na parede do rúmen, facilitando a entrada de bactérias ruminais, tendo como destaque, as do gênero Fusobacterium necrophorum, que devido à lesão prévia podem invadir a mucosa, ganhar a circulação porta, e ao chegar ao fígado provocar infecção e a formação de abscessos (Nagaraja \& Lechtenberg, 2007, Amachawadi \& Nagaraja, 2016).
Os abscessos hepáticos podem ocorrer em todas as idades, e em todos os tipos de rebanho, incluindo o leiteiro; porém exercem um impacto econômico maior em rebanhos alimentados com grãos (Amachawadi \& Nagaraja, 2016).

Devido à grande dificuldade em se diagnosticar essa enfermidade, na maioria das vezes os abscessos hepáticos são diagnosticados e encontrados no exame post-mortem durante o abate dos bovinos, pois em grande parte dos casos não há manifestação de sinais clínicos.

Diversos estudos têm buscado alternativas para a prevenção dos abscessos hepáticos em bovinos de corte, já que o uso dos antibióticos para tal finalidade tem sido cada vez mais contestado pelo fato de poder induzir a resistência antimicrobiana em seres humanos. Sendo assim, a vacinação, e a manipulação das dietas tem ganhado cada vez mais importância.

O objetivo desta revisão é reunir e discutir informações a respeito da incidência dos abscessos hepáticos em bovinos, bem como sua importância econômica, etiologia, patogenia, diagnóstico e prevenção. 


\section{Incidência}

A incidência de abscessos hepáticos em bovinos alimentados com grãos pode variar de $1 \mathrm{a}$ $2 \%$, até 90 a $95 \%$. No entanto, a prevalência na maioria dos confinamentos varia de 12 a $32 \%$ (Nagaraja \& Lechtenberg, 2007). Entretanto, dados recentes sugerem que a média se encontra entre 10 e $20 \%$ (Rezac et al., 2014). Com relação a incidência de abscessos hepáticos em bovinos confinados no Brasil, alguns trabalhos relatam a incidência de $2,5 \%$ e outros de $3,1 \%$ (Almeida et al., 2005, Vechiato et al., 2011). No estudo realizado por Vechiato et al. (2011) verificou-se que a frequência de abscessos hepáticos em bovinos não confinados foi relativamente alta (1,3\%). De acordo com diversos autores, as principais origens de abscessos após os quadros de ruminite são os secundários, aos casos de infecções umbilicais contraídas logo após o nascimento (Radostits et al., 2010). Essa grande variação na incidência dos abscessos hepáticos pode ser em parte explicada pelo envolvimento de inúmeros fatores, como, dieta, período de permanência no confinamento, aptidão do rebanho, raça, sexo, localização geográfica e período do ano. Todavia, a dieta é apontada como o principal fator modulador da incidência de abscesso hepático em bovinos (Amachawadi \& Nagaraja, 2016). A incidência é afetada pela quantidade e possivelmente pelo tipo de alimento empregado na dieta de terminação. Geralmente a incidência e a severidade dos abscessos aumentam à medida que a proporção de forragem na dieta diminui. Maior proporção de forragem tem a capacidade de promover uma fermentação ruminal mais estável, além de diminuir a variação no consumo dos alimentos, reduzindo então a incidência de acidose e ruminites (Nagaraja \& Chengappa, 1998). Contudo, alguns estudos não têm demonstrado diferença na incidência de abscesso hepático em dietas sem a inclusão de forragem ou contendo de 3 a $15 \%$ durante toda a fase de terminação (Stock et al., 1990). Além disso, as características físicas da forragem podem influenciar na incidência dos abscessos hepáticos. Em um estudo realizado por Utley et al. (1973) constatou-se que a incidência de abscessos hepáticos em novilhos submetidos a uma dieta contendo $80 \%$ de concentrado e $20 \%$ de casca de amendoim inteira, foi de $3,7 \%$. Porém, quando as cascas foram moídas ou peletizadas, a incidência aumentou para 56 e 59\%, respectivamente. De acordo com Mader et al. (1991), bovinos alimentados com dietas contendo forragem seca apresentam uma maior incidência de abscesso hepático quando comparados aos submetidos a dietas contendo silagem como fonte de volumoso, sendo que uma possível justificativa, seria a maior seleção dos alimentos por parte dos animais em dietas contendo forragem seca, o que contribui para o surgimento da acidose ruminal e subsequentemente dos abscessos hepáticos.

O tipo de grão utilizado na dieta dos bovinos também interfere na incidência dos abscessos hepáticos. Grãos que são classificados como rapidamente fermentáveis, tais como o trigo, cevada, milho grão úmido e o milho floculado, promovem maiores flutuações no $\mathrm{pH}$ ruminal e na ingestão dos alimentos, o que predispõe a acidose, ruminites e consequentemente ao surgimento dos abscessos hepáticos (Nagaraja \& Chengappa, 1998). O processamento de grãos, como a gelatinização dos grânulos de amido, tem a capacidade de aumentar a taxa de fermentação ruminal do amido, o que aumenta a probabilidade do desenvolvimento de acidose e abscessos hepáticos (Nagaraja et al., 2005).

Em relação a inclusão de subprodutos da agroindústria na dieta de ruminantes, com o intuito de diminuir os custos de produção, Wierenga et al. (2010) substituíram a cevada laminada à seco por resíduos secos e solúveis de destilaria (DDGS) em $20 \%$ da matéria seca (MS) da dieta de terminação. Os autores verificaram um aumento na incidência de abscessos hepáticos, o que corrobora com um trabalho realizado por Beliveau \& McKinnon (2008). Todavia, em um estudo realizado por Uwituze et al. (2010) objetivando avaliar a inclusão de DDGS em dietas contendo milho floculado, e utilizando silagem de milho ou feno de alfafa como fonte de volumoso. Os autores verificaram maior incidência de abscessos hepáticos $(11,1 \%)$ em bovinos submetidos a dietas com silagem de milho como fonte de volumoso e sem a inclusão de DDGS. Mader et al. (1991) relataram maior incidência de abscessos hepáticos em bovinos alimentados com milho grão úmido, em relação ao milho laminado seco. Entretanto, Stock et al. (1991) afirmaram não haver diferença.

Segundo Nagaraja \& Lechtenberg (2007) a incidência de abscessos hepáticos é de 1 a $3 \%$ maior para machos em relação as fêmeas, sendo que animais da raça Holandesa apresentam uma maior predisposição do que raças de corte. Uma possível explicação para a diferença entre os sexos seria o consumo de MS, já que machos geralmente consomem 1 a 3\% de MS a mais do que fêmeas. 
Outro fator preponderante seria o tempo de permanência no confinamento, onde comparando ambos os sexos e considerando pesos semelhantes, as fêmeas tendem a terminar mais cedo e por isso permanecem confinadas por um período menor. Os autores acrescentam que a maioria dos abscessos tende a se desenvolver nos últimos 60 dias de confinamento quando os teores de concentrado na dieta e ingestão de matéria seca são maiores.

A maior incidência de abscessos hepáticos em bovinos da raça holandesa é justificada pelo maior tempo de alimentação desses animais, e também pelo maior consumo de alimentos quando comparados aos bovinos de corte de peso semelhante (em média 12\% maior). Além disso, bovinos da raça holandesa apresentam uma maior incidência de distúrbios digestivos e mortes do que bovinos de corte (Amachawadi \& Nagaraja, 2016).

Os abscessos hepáticos são consequências da acidose e ruminite, portanto, falhas no manejo da dieta. Aumentar de forma brusca a energia da dieta, sem considerar as corretas proporções e intervalos requeridos para a adaptação da microbiota ruminal é capaz de induzir quadros de acidose e ruminite e consequentemente elevar a incidência de abscessos hepáticos (Nagaraja \& Chengappa, 1998). No entanto, os dados da literatura referentes as práticas de alimentação e incidência de abscessos hepáticos ainda são insuficientes. Alguns autores desconhecem porque bovinos de determinadas baias de um mesmo confinamento, apresentam uma alta incidência de abscessos hepáticos quando comparados a uma baixa incidência de bovinos de baias adjacentes, recendo uma mesma dieta (Nagaraja \& Chengappa, 1998).

\section{Importância econômica}

Os abscessos hepáticos são considerados o maior problema econômico para produtores e também para a indústria frigorifica, já que são associados a uma diminuição no consumo da dieta, ganho de peso e rendimento de carcaça (Nagaraja \& Lechtenberg, 2007).

De acordo com o mais recente relatório nacional de auditoria de qualidade de carne, $20,9 \%$ dos fígados foram condenados no abate, sendo que os abscessos hepáticos representaram cerca de dois terços dos fígados condenados (McKeith et al., 2012). Em um estudo realizado por Baptista \& Moreira (1999), em alguns frigoríficos brasileiros foi observado condenação de $50.405(8,29 \%)$ em 607.346 fígados analisados. Sendo que em relação as enfermidades encontradas, a teleangiectasia foi responsável pela maior $(25,1 \%)$ causa de condenação (12.663 fígados), seguido por abscessos hepáticos $(24,3 \%)$.

O fígado representa cerca de $2 \%$ do peso da carcaça, portanto, sua perda já representa um prejuízo financeiro. Todavia, o maior impacto econômico causado pelos abscessos hepáticos, diz respeito a redução do desempenho animal e do rendimento de carcaça. De acordo com Nagaraja \& Chengappa (1998), bovinos com abscesso hepático apresentam uma diminuição no consumo da dieta, no ganho de peso, eficiência alimentar e na porcentagem de gordura na carcaça.

O impacto econômico é altamente dependente da severidade dos abscessos hepáticos. Com base no número e no tamanho dos abscessos hepáticos, os mesmos são classificados em uma escala de 1 a 3, ou como A-, A e A+ (moderado a severo, respectivamente), sendo referido como o Sistema de Pontuação Elanco (Nagaraja \& Chengappa, 1998).

Geralmente, os abscessos hepáticos com uma pontuação A- (1) ou A (2) não tem um efeito mensurável no desempenho e características de carcaça dos bovinos, ao passo que os $\mathrm{A}+$ são passiveis de provocar perdas econômicas ao produtor. Em um estudo realizado por Brown \& Lawrence (2010), com o objetivo de avaliar a incidência de abscessos hepáticos sobre $\mathrm{o}$ desempenho animal e também quanto ao impacto na classificação e valor da carcaça, constatou-se que o maior impacto econômico foi em bovinos com abscessos $\mathrm{A}+$, principalmente naqueles que tiveram adesões ao diafragma ou órgãos abdominais.

De acordo com Brink et al. (1990), bovinos com abscessos hepáticos severos podem ter uma redução de até $11 \%$ no ganho de peso diário e ainda uma diminuição na eficiência alimentar de $9,7 \%$. Este mesmo autor compilou dados de 12 experimentos, os quais avaliaram a severidade dos abscessos hepáticos sobre a ingestão e eficiência alimentar de 566 bovinos, alimentados individualmente, sendo a dieta baseada em grãos de milho laminados a seco. Os resultados encontrados foram que o grupo de bovinos com abscessos hepáticos mais severos $(\mathrm{A}+$ ) diferiu do grupo de bovinos sem abscessos em relação a ingestão diária de alimento, ganho de peso e 
eficiência alimentar. Os respectivos valores para tais parâmetros foram menores quando comparados aos sem abscessos. Além disso, bovinos com abscesso severos podem exigir uma maior limpeza da carcaça devido a adesão dos abscessos ao diafragma e aos órgãos adjacentes, e em alguns casos, a condenação de todas as vísceras pode se fazer necessária, o que representa um grande impacto aos frigoríficos. Em um estudo realizado em rebanhos comerciais do Texas, constatou-se que o rendimento de carcaça foi maior $(1,6 \%)$ em bovinos com fígados normais, quando comparados aos bovinos com abscessos hepáticos severos (A+) Montgomery (1985) citado Nagaraja \& Chengappa (1998). O que corrobora com o relatado por Brink et al. (1990). Entretanto, Wierenga et al. (2010) avaliando a substituição da silagem de cevada e da cevada laminada à seco, por DDGS em diferentes dietas, verificaram um aumento na incidência de abscessos hepáticos com a substituição. Todavia, não constataram uma redução no desempenho animal, e ainda, as características de carcaça não foram afetadas. Ainda com relação aos prejuízos que os abscessos hepáticos podem provocar, quando há uma ruptura acidental de um abscesso e contaminação da carcaça na linha de abate, a mesma é desviada, interrompendo o fluxo, e consequentemente causando uma dispendiosa perda de tempo e trabalho (Nagaraja \& Chengappa, 1998).

\section{Etiologia}

Diversos pesquisadores têm avaliado a flora bacteriana anaeróbica e aeróbica de abscessos de fígado bovino. Quase todos os estudos concluíram que o Fusobacterium necrophorum, anteriormente denominado de Sphaerophorus necrophorus é o principal agente etiológico. O mesmo também está implicado como principal patógeno causador da laringite necrótica dos bezerros, footrot e abscessos dos cascos de bovinos. A incidência do Fusobacterium necrophorum, isolado a partir da cultura dos abscessos hepáticos, tem variado de 81 a $100 \%$. Em alguns casos, o microrganismo é envolvido como patógeno único, mas frequentemente está associado a uma variedade de outras bactérias anaeróbias e facultativas (Nagaraja \& Chengappa, 1998, Nagaraja \& Lechtenberg, 2007, Amachawadi \& Nagaraja, 2016).

O segundo patógeno mais frequentemente isolado é o Arcanobacterium pyogenes, sendo que atualmente, o mesmo é denominado de
Trueperella pyogenes (Amachawadi \& Nagaraja, 2016). A prevalência nos abscessos hepáticos tem variado de 0 a $50 \%$ (Nagaraja et al., 1999). A origem do mecanismo patogênico desse microrganismo não é bem compreendida; porém há alguns indícios de que haja um sinergismo patogênico entre $A$. pyogenes e o $F$. necrophorum (Amachawadi \& Nagaraja, 2016).

Uma diversidade de outras bactérias anaeróbias e facultativas, incluindo Bacteriodes spp., Clostridium spp., Escherichia coli, Klebsiella spp., Enterobacter spp., Mobilincus spp., Pasteurella spp., Peptostreptococcus spp., Porphyromonas spp., Prevotella spp., Propionibacterium spp., Staphylococcus spp., Streptococcus spp, além de várias outras gram positivas e gram negativas não identificadas tem sido isoladas a partir de abscessos hepáticos de bovinos provenientes de confinamentos (Nagaraja \& Chengappa, 1998, Nagaraja \& Lechtenberg, 2007, Amachawadi \& Nagaraja, 2016).

Em um estudo realizado por Amachawadi \& Nagaraja (2016) utilizando 10 amostras de abscessos hepáticos, isolou-se o Fusobacterium necrophorum em todos os dez abscessos (100\%) e Trueperella pyogenes foi isolada de quatro abscessos. Surpreendentemente, a Salmonella enterica foi isolada de todas as dez amostras inoculadas em placas de ágar sangue e incubadas anaerobicamente, sendo o primeiro relato de isolamento de Salmonella enterica em abscessos hepáticos de bovinos. A hipótese mais plausível para esse fato, seria que este microrganismo, presente no intestino delgado ou grosso, poderia atravessar a barreira do epitélio intestinal, atingindo a circulação porta e com isso chegar ao fígado e iniciar a infecção. Porém, mais estudos são necessários para entender a importância e a incidência da Salmonela em abscessos hepáticos de bovinos. O Fusobacterium necrophorum foi reconhecido como um patógeno animal no final do ano de 1880. Trata-se de uma bactéria Gramnegativa, anaeróbia, com formato de bastão, imóvel e não formadora de esporos. Tal espécie, geralmente não fermenta nenhum carboidrato, embora algumas cepas podem fracamente fermentar a glicose. O seu principal substrato energético é o ácido láctico, que é fermentado principalmente em acetato, butirato e também em propionato; porém em menores quantidades. É ainda considerado uma das mais importantes bactérias que degradam a lisina no rúmen (Nagaraja \& Chengappa, 1998, Amachawadi \& Nagaraja, 2016). Historicamente o Fusobacterium 
necrophorum é classificado em 4 biotipos: A, B, $\mathrm{AB}$ e C. O biótipo $\mathrm{C}$ não é considerado virulento, e foi reclassificado em uma nova espécie (Fusobacterium pseudonecrophorum). Já o A e B, são os encontrados mais frequentemente nos abscessos hepáticos, sendo designados como subespécie necrophorum e funduliforme, respectivamente. $\mathrm{O}$ biótipo $\mathrm{AB}$ é isolado de forma mais frequente de lesões de cascos dos bovinos e ovinos e raramente em abscessos hepáticos (Amachawadi \& Nagaraja, 2016). As subespécies necrophorum e funduliforme se diferem na morfologia celular, padrões de crescimento e características bioquímicas e biológicas. Entre as características biológicas, a mais importante para a diferenciação diz respeito a produção de fatores de virulência, os quais possuem grande relevância para o desenvolvimento dos abscessos hepáticos.

A subespécie necrophorum é isolada com maior frequência dos abscessos hepáticos $(71$ a 95\%) quando compara a subespécie funduliforme (5 a 29\%), o que demonstra uma maior virulência (Nagaraja \& Chengappa, 1998, Amachawadi \& Nagaraja, 2016).

Diversas toxinas estão envolvidas como fatores de virulência na patogênese das infecções por Fusobacterium necrophorum. Estas incluem leucotoxina, endotoxinas de lipopolissacarideos, hemolisina, hemaglutinina, fator de agregação plaquetária, toxina dermonecrótica, e outras enzimas extracelulares, como proteases e desoxirribonuclease (Nagaraja \& Chengappa, 1998, Amachawadi \& Nagaraja, 2016).

Entre estes fatores, leucotoxina e endotoxina de lipopolissacarideos são os mais estudados, além de serem apontados como os principais fatores de virulência envolvidos na infecção por fusobactéria. A importância da leucotoxina como um dos principais fatores de virulência é evidenciada pela correlação entre a produção da toxina e a capacidade de induzir abscessos hepáticos em animais de laboratório, e também pela incapacidade das cepas que não produzem leucotoxinas para induzir abscessos nos cascos de bovinos após inoculação intra-dérmica (Amachawadi \& Nagaraja, 2016).

Sendo assim, a diferença na virulência entre as duas subespécies, é atribuída a diferença na quantidade e na composição do lipopolissacarideo, além da quantidade de leucotoxina produzida. Diversos estudos apontam que a subespécie necrophorum produz mais toxina em relação à funduliforme (Nagaraja \&
Chengappa, 1998, Amachawadi \& Nagaraja, 2016).

O Fusobacterium necrophorum é um habitante normal do trato gastrointestinal de mamíferos, sendo isolado do conteúdo ruminal de bovinos alimentados com diversas dietas. Sua concentração no rúmen é baixa $\left(<10^{6}\right)$, entretanto a mesma é altamente influenciada pela dieta, e aumenta em bovinos alimentados com dietas à base de grãos, comparado com as dietas à base de forragem. Isso é explicado pela maior disponibilidade do lactato em dietas à base de grãos, já que o Fusobacterium necrophorum utiliza o lactato como principal substrato energético. Com o acumulo de lactato, o pH ruminal diminui $(<5.5)$ e o crescimento da fusobactéria é inibido. Porém, a acidez ruminal é um fator predisponente para tornar a parede ruminal mais susceptível a entrada e colonização pelo Fusobacterium necrophorum, que também tem a capacidade de aderir a parede ruminal devido à sua aerotolerância e habilidade para crescer em ph fisiológico (Nagaraja \& Chengappa, 1998, Amachawadi \& Nagaraja, 2016). O Fusobacterium necrophorum é frequentemente isolado das paredes ruminais que apresentam paraqueratose e ruminites, e menos frequente do epitélio ruminal intacto.

\section{Patogênese}

Os abscessos hepáticos são considerados sequelas de quadros de acidose ruminal e ruminites em bovinos alimentados com dietas ricas em carboidratos altamente fermentáveis, e pobres em volumoso. Smith (1944) citado por Nagaraja \& Chengappa (1998) foi o primeiro a observar a relação entre os abscessos hepáticos e lesões no rúmen em bovinos confinados, sendo mais tarde confirmada por Jensen et al. (1954) citado por Nagaraja \& Chengappa (1998).

Mas, em um estudo realizado por Rezac et al. (2014) sobre a relação entre saúde ruminal e os abscessos hepáticos, verificou-se que $32 \%$ dos bovinos com ruminite moderada ou grave apresentaram abscessos hepáticos, já aqueles com a parede ruminal saudável a incidência foi de $19 \%$.

A ruminite induzida pela acidose ruminal e também os danos à superfície protetora do rúmen, geralmente estão relacionados com erros no manejo dietético dos animais, sendo que podemos citar como falhas comuns, o súbito aumento de energia nas dietas, baixa inclusão de forragem, fornecimento de dietas de baixa palatabilidade e 
ainda longos períodos de restrição alimentar. O dano ao rúmen ainda pode ser agravado pela presença de objetos estranhos na dieta, como partículas pontiagudas, ou pelos (Nagaraja \& Chengappa, 1998, Nagaraja et al., 2005).

A parede ruminal danificada em decorrência da acidose ou devido a penetração de objetos estranhos, torna-se susceptível a invasão e colonização pelo Fusobacterium necrophorum; sendo que após a colonização, o mesmo pode conseguir entrar na corrente sanguínea ou causar abscessos na parede ruminal, e de forma subsequente causar uma embolia bacteriana na circulação portal. As bactérias presentes na circulação são filtradas pelo fígado, desencadeando um quadro de infecção e formação de abscessos (Nagaraja \& Chengappa, 1998, Amachawadi \& Nagaraja, 2016). Outras portas de entrada para as bactérias no parênquima hepático, tornando possível o estabelecimento de uma infecção, incluem a artéria hepática, a veia umbilical (bezerros neonatos) e a ramificação biliar (Vechiato et al., 2011).

Indiscutivelmente, os fatores de virulência do Fusobacterium necrophorum desempenham um papel crucial na invasão e colonização do epitélio ruminal, e ainda na entrada e estabelecimento da infecção no fígado. A atividade das proteases, a ação dermonecrótica e o efeito citotóxico das leucotoxinas nas células ruminais auxiliam na penetração e colonização da parede do rúmen (Nagaraja \& Chengappa, 1998, Amachawadi \& Nagaraja, 2016).

O fígado é um órgão altamente vascularizado, portanto extremamente oxigenado, e ainda conta com um poderoso sistema de defesa, devido à presença de numerosas células fagocíticas (leucócitos e células de Kupffer). Deste modo, como o Fusobacterium necrophorum é um microrganismo anaeróbico, o mesmo precisa superar tanto a alta concentração de oxigênio, como os mecanismos fagocíticos para sobreviver, proliferar e iniciar a formação dos abscessos (Nagaraja \& Chengappa, 1998, Amachawadi \& Nagaraja, 2016). Portanto, a leucotoxina e o lipopolissacarideo endotóxico do Fusobacterium necrophorum podem protegê-lo da fagocitose. Além disso, a liberação de produtos citolíticos, tais como enzimas lisossômicas e metabolitos do oxigênio em decorrência da destruição de fagócitos, tem um efeito prejudicial sobre o parênquima hepático (Nagaraja \& Chengappa, 1998).
O sinergismo com bactérias facultativas, a coagulação intravascular induzida pelo lipopolissacarideo endotóxico, o fator de agregação plaquetária, a formação de abscessos encapsulados com fibrina e ainda o comprometimento do transporte do oxigênio, devido ao dano aos eritrócitos pela ação da hemolisina, são capazes de contribuir para o estabelecimento de um microambiente anaeróbio propício para o crescimento de bactérias anaeróbicas dentro da parede do rúmen ou no fígado (Nagaraja e Chengappa (Nagaraja \& Chengappa, 1998, Nagaraja \& Lechtenberg, 2007, Amachawadi \& Nagaraja, 2016).

\section{Diagnóstico}

Na maioria das vezes, os abscessos hepáticos são detectados apenas no momento do abate, já que em bovinos, mesmo quando há uma grande quantidade de pequenos abscessos ou de grandes abscessos, raramente há a manifestação de sinais clínicos (Nagaraja \& Chengappa, 1998). Ocasionalmente os bovinos manifestam um quadro de dor abdominal, e ainda com menor frequência há ruptura de um abscesso superficial ou erosão, e também perfuração da veia cava caudal, que é passível de provocar uma extensa disseminação e infecção em outros órgãos, e inclusive morte (Nagaraja \& Chengappa, 1998). Geralmente, hematologia e testes de função hepática não são indicadores confiáveis para se firmar um diagnóstico de abscesso hepático. Porém, alguns autores relatam que em casos de indução experimental de abscessos hepáticos através da inoculação do Fusobacterium necrophorum, a indicação da disfunção é devido a uma elevação das proteínas séricas, bilirrubina e enzimas como a g-glutamiltransferase e sorbitol desidrogenase (Nagaraja \& Chengappa, 1998, Nagaraja \& Lechtenberg, 2007).

Uma técnica de imagem, que permite a visualização de tecidos moles de órgãos internos é a ultrassonografia, a qual já foi testada para a detecção de abscessos hepáticos. Em um trabalho realizado por Lechtenberg \& Nagaraja (1991) observou-se a presença de abscessos hepáticos após o terceiro dia em induções experimentais, sendo que os mesmos variaram de 0,5 a $10 \mathrm{~cm}$.

O fígado é um excelente órgão para a realização da imagem ultrassonográfica, devido a consistência do seu tecido e localização, sendo que esta técnica é amplamente utilizada em animais de pequeno porte. A técnica é extremamente útil para 
monitorar o início e a evolução de abscessos hepáticos induzidos experimentalmente, e quando o local da injeção é conhecido. Porém, sua aplicação comercial em bovinos confinados e com abscessos desenvolvendo de forma natural é limitada, já que o exame ultrassonográfico não é capaz de visualizar todo o fígado, particularmente o lado esquerdo voltado para os órgãos internos e ainda partes de determinados lobos que são cobertos por órgãos como pulmões e rins. Além disso, há consequências produtivas, como estresse, tempo de manejo e redução no ganho de peso diário (Nagaraja \& Lechtenberg, 2007).

\section{Prevenção}

Esforços vêm sendo conduzidos para prevenir e reduzir a incidência de abscessos hepáticos em bovinos, principalmente nos confinados, já que os prejuízos causados por essa patologia refletem em uma diminuição no lucro final do produtor e da indústria frigorifica. $\mathrm{O}$ controle de abscessos hepáticos em bovinos confinados é na sua maior parte dependente do uso de compostos antimicrobianos na alimentação, aliado a um manejo nutricional adequado, a fim de minimizar a ocorrência de acidose ruminal e ruminite. Com base no compêndio de aditivos alimentares, seis antibióticos (bacitracina metil-disalicilato, clorotetraciclina, sulfato de neomicina em combinação com oxitetraciclina, oxitetraciclina, tilosina e virginiamicina) são aprovados para a prevenção de abscessos hepáticos em bovinos confinados (Nagaraja \& Chengappa, 1998, Amachawadi \& Nagaraja, 2016).

Esses antibióticos apresentam uma variação nos efeitos inibitórios sobre o Fusobacterium necrophorum e $T$. pyogenes, e ainda em relação a eficácia na prevenção dos abscessos hepáticos. Bacitracina é o menos eficaz, ao passo que a tilosina é o mais eficaz dos antibióticos e ainda o mais utilizado nas dietas para bovinos em confinamento. Acredita-se que o modo de ação da tilosina se dá pelo seu efeito inibitório sobre o Fusobacterium necrophorum no rúmen, fígado ou em ambos, porém mesmo ela sendo parcialmente absorvida pelo intestino e deste modo poder atingir o fígado, é provável que seu efeito primário seja no rúmen (Nagaraja \& Chengappa, 1998, Amachawadi \& Nagaraja, 2016). Wileman et al. (2009) realizaram uma meta-análise com o intuito de avaliar os riscos de incidência de abscessos hepáticos em bovinos que receberam tilosina e naqueles que não receberam tilosina em sistemas de alimentação convencionais, e constatou-se que em dietas contendo tilosina, houve uma redução nos riscos de abscessos hepáticos de $30 \%$ para $8 \%$. $\mathrm{O}$ que corrobora com um trabalho realizado por Meyer et al. (2009) que verificaram uma menor incidência de abscessos hepáticos em novilhos alimentados com dietas contendo tilosina (90 $\mathrm{mg} / \mathrm{cabeça/dia),} \mathrm{em} \mathrm{relação} \mathrm{a} \mathrm{dietas} \mathrm{sem} \mathrm{tilosina.}$ Todavia, Depenbusch et al. (2008) realizaram um trabalho com novilhas submetidas a dietas tendo como base o milho floculado com ou sem a adição de grãos de milhos húmidos destilados com solúveis, e verificaram que a adição de tilosina (90mg/cabeça/dia) em dietas contendo milho floculado tendeu a reduzir a severidade dos abscessos hepáticos, ao passo que em dietas contendo grãos de milhos húmidos destilados com solúveis não houve diferença.

O uso de antibióticos na alimentação animal representa um risco para a saúde humana, já que pode induzir a resistência antimicrobiana. Em alguns países da Europa, o uso de antibióticos para a profilaxia de doenças em bovinos, está proibido, porém, em determinados países como nos Estados Unidos, o governo sugere que antibióticos como a tilosina são usados para prevenir e assegurar a saúde do animal e não para promover $o$ crescimento, permitindo então o seu uso. Entretanto, a partir de janeiro de 2017, o uso da tilosina em bovinos confinados para a prevenção dos abscessos hepáticos, deverá estar sob supervisão veterinária ((FDA, 2015, Amachawadi \& Nagaraja, 2016). Sendo assim, é de suma importância buscar alternativas para a prevenção dos abscessos hepáticos, pois é provável que em um determinado momento os pecuaristas sejam obrigados a deixar de usar antibióticos para esse fim.

Trabalhos estão sendo realizados com o uso de óleos essenciais e vacinas, objetivando avaliar a eficácia desses métodos para a prevenção dos abscessos hepáticos. Em um trabalho realizado por Samii et al. (2016) verificou-se que a inclusão de um óleo essencial (limoneno) na dieta, diminuiu de forma linear a concentração do Fusobacterium necrophorum no rúmen de bovinos canulados, sugerindo ser capaz de reduzir a incidência de abscessos hepáticos. Elwakeel et al. (2013) avaliaram o efeito de cinco óleos essenciais (eugenol, vanilina, timol, guaiacol e limoneno) e de um produto comercial (CRINA), sobre o crescimento do Fusobacterium necrophorum e observaram que o limoneno, a 20 ou $100 \mu \mathrm{g} / \mathrm{mL}$ e timol, a $100 \mu \mathrm{g} / \mathrm{mL}$, inibiram o crescimento do Fusobacterium necrophorum, 
enquanto que o eugenol, guaiacol, vanilina e CRINA não tiveram efeito. Esses dados corroboram em parte com os encontrados por Meyer et al. (2009) que constataram uma redução na incidência de abscessos hepáticos em dietas com a inclusão de um produto comercial contendo limoneno e timol, em relação ao grupo controle.

Os antibióticos utilizados na dieta para bovinos reduzem a incidência de abscessos hepáticos nos mesmos, porém não eliminam o problema. Desta forma, uma vacina eficaz seria altamente desejável para a indústria de confinamento. Outro fato de extrema relevância seria em relação a saúde pública, permitindo resolver problemas de resistência antimicrobiana em humanos, já que os antibióticos são usados com frequência na dieta de bovinos confinados (Amachawadi \& Nagaraja, 2016).

Até os dias de hoje, apenas duas vacinas atingiram aplicação comercial. Sendo uma bacteriana (Fusobacterium necrophorum), conhecida por Fusogard (Elanco saúde animal), a qual foi aprovada para o controle de abscessos hepáticos e podridão dos cascos, e outra comercializada como Centurion (Merck saúde animal),que consistiu de uma combinação de leucotoxóide do Fusobacterium necrophorum e uma bacteriana (Trueperella pyogenes), que mostrou ser capaz de reduzir a prevalência de abscessos hepáticos em bovinos, mas atualmente não está disponível comercialmente (Amachawadi \& Nagaraja, 2016). Checkley et al. (2005) realizaram um estudo de campo, de forma aleatória, para avaliar a eficácia de uma vacina (Fusogard) no controle de abscessos hepáticos e podridão dos cascos em bovinos de confinamentos comerciais do oeste do Canada. Os autores relataram que a vacina foi capaz de reduzir a incidência de abscessos hepáticos $\mathrm{A}$ ou $\mathrm{A}+\mathrm{em}$ rebanhos com baixa prevalência (10\%), os quais tiveram livre acesso a forragem, porém não foi efetiva em rebanhos com alta prevalência (32\%), onde os animais foram submetidos a dietas de alto grão. Esses dados corroboram em parte com um trabalho realizado por Fox et al. (2009) os quais avaliaram a eficácia de duas vacinas (Fusogard e Centurion) na redução da incidência de abscessos hepáticos em bovinos confinados recebendo uma dieta com $73 \%$ de milho floculado e $13 \%$ de forragem. Os autores relataram que ambas as vacinas não afetaram a incidência de abscessos severos (A+) ou totais, sendo a mesma de $39 \%$ e $56 \%$, respectivamente.
Narayanan et al. (2003) avaliaram a eficácia da leucotoxina recombinante do Fusobacterium necrophorum em ratos de laboratório, sendo que o gene que codifica a leucotoxina (lktA) foi clonado, sequenciado e expresso na Escherichia coli. Cinco polipeptídios recombinantes (BSBSE, SX, GAS, SH e FINAL) foram expressos na E. coli e purificados por cromatografia. Constatou-se que todos os poli peptídeos foram imunogênicos, porém o BSBSE e o SH induziram uma proteção significativa nos ratos contra o Fusobacterium necrophorum. Entretanto, a eficácia desses polipeptídios em bovinos não foi avaliada.

Outro antígeno do Fusobacterium necrophorum que é visto com potencialidade para o desenvolvimento de vacinas, é a proteína de membrana externa, a qual é responsável por intermediar a adesão do Fusobacterium necrophorum ás células bovinas (Amachawadi \& Nagaraja, 2016). Além da inclusão de compostos antimicrobianos na ração, óleos essenciais, e de possíveis praticas imunizadoras para a prevenção dos abscessos hepáticos em bovinos, o bom manejo de cocho objetivando evitar o desequilíbrio ruminal é um fator chave para o controle efetivo de abscessos hepáticos. Outras recomendações incluem a adaptação dos bovinos à dietas de alto grão, evitando-se sub ou superalimentação, e o fornecimento da dieta várias vezes ao dia; o aumento do teor de volumoso da ração, o rigoroso controle de mistura da dieta, espaço de cocho adequado, e água fresca e limpa, são outros itens essenciais para se evitar os distúrbios metabólicos e suas consequências, entras elas os abscessos hepáticos (Nagaraja \& Chengappa, 1998, Amachawadi \& Nagaraja, $\underline{\text { 2016). }}$.

\section{Considerações finais}

Os abscessos hepáticos impactam economicamente os produtores e a indústria frigorifica devido à redução do desempenho dos animais e condenação do órgão, respectivamente. Embora os antibióticos adicionados á dieta dos bovinos confinados sejam eficazes em reduzir a incidência dos abscessos, os mesmos não resolvem totalmente o problema, e, além disso, podem induzir a resistência antimicrobiana na população humana, o que torna o seu uso cada vez mais questionável. Em alguns estudos com vacinas, as mesmas não se mostraram eficazes em diminuir a incidência quando as dietas foram desafiadoras (alto-grão), demonstrando que são necessárias mais pesquisas para a produção de 
vacinas eficientes. A leucotoxina e proteínas de membrana externa do Fusobacterium necrophorum são antígenos tidos como potenciais para o desenvolvimento de vacinas.

\section{Referências bibliográficas}

Almeida, L. P. d., Reis, D. O. \& Carrijo, K. d. F. 2005. Abscessos hepáticos como causa de condenações em bovinos de abate. Higiene Alimentar, 19, 51-53.

Amachawadi, R. G. \& Nagaraja, T. G. 2016. Liver abscesses in cattle: A review of incidence in Holsteins and of bacteriology and vaccine approaches to control in feedlot cattle. Journal of Animal Science, 94, 1620-1632.

Baptista, E. C. \& Moreira, F. 1999. Causas de condenaçäo de fígados bovinos em frigoríficos de Minas Gerais e perdas econômicas associadas. Revista Higiene Alimentar, 13, 22 27.

Beliveau, R. M. \& McKinnon, J. J. 2008. Effect of graded levels of wheat-based dried distillers' grains with solubles on performance and carcass characteristics of feedlot steers. Canadian Journal of Animal Science, 88, 677684.

Brink, D. R., Lowry, S. R., Stock, R. A. \& Parrott, J. C. 1990. Severity of liver abscesses and efficiency of feed utilization of feedlot cattle. Journal of Animal Science, 68, 1201-1207.

Brown, T. R. \& Lawrence, T. E. 2010. Association of liver abnormalities with carcass grading performance and value. Journal of Animal Science, 88, 4037-4043.

Checkley, S. L., Janzen, E. D., Campbell, J. R. \& McKinnon, J. J. 2005. Efficacy of vaccination against Fusobacterium necrophorum infection for control of liver abscesses and footrot in feedlot cattle in western Canada. The Canadian Veterinary Journal, 46, 1002-1007.

Depenbusch, B. E., Loe, E. R., Quinn, M. J., Corrigan, M. E., Gibson, M. L., Karges, K. K. \& Drouillard, J. S. 2008. Corn distillers grains with solubles derived from a traditional or partial fractionation process: Growth performance and carcass characteristics of finishing feedlot heifers 1. Journal of Animal Science, 86, 2338-2343.

Elwakeel, E. A., Amachawadi, R. G., Nour, A. M., Nasser, M. E. A., Nagaraja, T. G. \& Titgemeyer, E. C. 2013. In vitro degradation of lysine by ruminal fluid-based fermentations and by Fusobacterium necrophorum. Journal of Dairy Science, 96, 495-505.

FDA. 2015. Food and Drug Administration of the US, Substances used as GRAS in food. 21, CFR 184.

Fox, J. T., Thomson, D. U., Lindberg, N. N. \& Barling, K. 2009. A comparison of two vaccines to reduce liver abscesses in naturalfed beef cattle. Bovine Practitioner, 43, 168174.

Lechtenberg, K. F. \& Nagaraja, T. G. 1991. Hepatic ultrasonography and blood changes in cattle with experimentally induced hepatic abscesses. American Journal of Veterinary Research, 52, 803-809.

Mader, T. L., Dahlquist, J. M. \& Schmidt, L. D. 1991. Roughage sources in beef cattle finishing diets. Journal of Animal Science, 69, 462-471.

McKeith, R. O., Gray, G. D., Hale, D. S., Kerth, C. R., Griffin, D. B., Savell, J. W., Raines, C. R., Belk, K. E., Woerner, D. R. \& Tatum, J. D. 2012. National Beef Quality Audit-2011: Harvest-floor assessments of targeted characteristics that affect quality and value of cattle, carcasses, and byproducts. Journal of Animal Science, 90, 5135-5142.

Meyer, N. F., Erickson, G. E., Klopfenstein, T. J., Greenquist, M. A., Luebbe, M. K., Williams, P. \& Engstrom, M. A. 2009. Effect of essential oils, tylosin, and monensin on finishing steer performance, carcass characteristics, liver abscesses, ruminal fermentation, and digestibility. Journal of Animal Science, 87, 2346-2354.

Nagaraja, T. G., Beharka, A. B., Chengappa, M. M., Carroll, L. H., Raun, A. P., Laudert, S. B. \& Parrott, J. C. 1999. Bacterial flora of liver abscesses in feedlot cattle fed tylosin or no tylosin. Journal of Animal Science, 77, 973978.

Nagaraja, T. G. \& Chengappa, M. M. 1998. Liver abscesses in feedlot cattle: A review. Journal of Animal Science, 76, 287-298.

Nagaraja, T. G. \& Lechtenberg, K. F. 2007. Liver abscesses in feedlot cattle. Veterinary Clinics of North America: Food Animal Practice, 23, 351-369.

Nagaraja, T. G., Narayanan, S. K., Stewart, G. C. \& Chengappa, M. M. 2005. Fusobacterium necrophorum infections in animals: pathogenesis and pathogenic mechanisms. Anaerobe, 11, 239-246. 
Narayanan, S. K., Chengappa, M. M., Stewart, G. C. \& Nagaraja, T. G. 2003. Immunogenicity and protective effects of truncated recombinant leukotoxin proteins of Fusobacterium necrophorum in mice. Veterinary Microbiology, 93, 335-347.

Prado, I. N. 2010. Produção de bovinos de corte e qualidade da carne. Eduem, Maringá, Paraná, Brasil.

Radostits, O. M., Gay, C. C., Blood, D. C., Hinchcliff, K. W. \& McKenzie, R. A. 2010. Clínica Veterinária: um tratado de doenças dos bovinos, ovinos, suínos, caprinos $e$ eqüinos. Guanabara Koogan, Rio de Janeiro.

Rezac, D. J., Thomson, D. U., Bartle, S. J., Osterstock, J. B., Prouty, F. L. \& Reinhardt, C. D. 2014. Prevalence, severity, and relationships of lung lesions, liver abnormalities, and rumen health scores measured at slaughter in beef cattle. Journal of Animal Science, 92, 2595-2602.

Samii, S. S., Wallace, N., Nagaraja, T. G., Engstrom, M. A., Miesner, M. D., Armendariz, C. K. \& Titgemeyer, E. C. 2016. Effects of limonene on ruminal Fusobacterium necrophorum concentrations, fermentation, and lysine degradation in cattle. Journal of Animal Science, 94, 3420-3430.

Stock, R. A., Sindt, M. H., Cleale, R. M. \& Britton, R. A. 1991. High-moisture corn utilization in finishing cattle. Journal of Animal Science, 69, 1645-1656.

Stock, R. A., Sindt, M. H., Parrott, J. C. \& Goedeken, F. K. 1990. Effects of grain type, roughage level and monensin level on finishing cattle performance. Journal of Animal Science, 68, 3441-3455.

Utley, P. R., Hellwig, R. E., Butler, J. L. \& McCormick, W. C. 1973. Comparison of unground, ground and pelleted peanut hulls as roughage sources in steer finishing diets. Journal of Animal Science, 37, 608-611.

Uwituze, S., Parsons, G. L., Shelor, M. K., Depenbusch, B. E., Karges, K. K., Gibson, M. L., Reinhardt, C. D., Higgins, J. J. \& Drouillard, J. S. 2010. Evaluation of dried distillers grains and roughage source in steamflaked corn finishing diets. Journal of Animal Science, 88, 258-274.

Vechiato, T. A. F., Maschio, W., Bom, L. C., Lopes, P. D. \& Ortolani, E. L. 2011. Retrospective study of liver abscesses in beef cattle slaughtered in a Brazilian abattoir. Brazilian Journal of Veterinary Research and Animal Science, 48, 384-391.

Wierenga, K. T., McAllister, T. A., Gibb, D. J., Chaves, A. V., Okine, E. K., Beauchemin, K. A. \& Oba, M. 2010. Evaluation of triticale dried distillers grains with solubles as a substitute for barley grain and barley silage in feedlot finishing diets. Journal of Animal Science, 88, 3018-3029.

Wileman, B. W., Thomson, D. U., Reinhardt, C. D. \& Renter, D. G. 2009. Analysis of modern technologies commonly used in beef cattle production: Conventional beef production versus nonconventional production using meta-analysis. Journal of Animal Science, 87, 3418-3426.

\section{Article History:}

Received 9 January 2018

Accepted 27 February 2018

Available online 9 April 2018

License information: This is an open-access article distributed under the terms of the Creative Commons Attribution License 4.0, which permits unrestricted use, distribution, and reproduction in any medium, provided the original work is properly cited. 